\title{
Research on television animation creation based on 3D digital technology
}

\author{
Youtian Ye $\mathrm{e}^{1,2, \mathrm{a}}$ \\ ${ }^{1}$ Wuhan University of Technology, 430070 Wuhan China \\ ${ }^{2}$ HuBei Institute of Fine Arts,430205,Wuhan,Hubei China \\ a53341620@qq.com
}

Keywords: television , animation creation ,3D digital technology

\begin{abstract}
D digital technology . As the result of the development 3D digital technology, the animation art developed rapidly . Combining the 3D digital technology and the traditional animation technology make the emerging animation art appearing form developed, and it help expand emerging creation field for animation art . The influence of 3D technology is diversified for animation creation . This paper analyze the creation process of three-dimensional animation and investigate the application of scene, tone designing, action and role modeling in animation creation .
\end{abstract}

\section{Introduction}

Television animation can bring unlimited fun and imagine for human by using the manner of television showing . And the television animation have unique attraction for the young people , and it play a very important role in socialist spiritual civilization. Television animation is the emerging culture and arts form ,it has unique attractiveness and creativity ${ }^{[1]}$. And with the development of 3D digital technology, the animation creation has entered a new creation field. And the support of 3D digital technology make the animation art get broader creation space .

\section{D digital technology overview}

The 3D digital technology is produced with the development of the computer hardware , and we also call it three-dimensional technology . Because the production costs of 3D technology is higher at the early period, we can only see it in the CCTV and overseas channels. However , the 3D digital technology is application in television stunt, column packing, advertisement design . And the application of 3D technology in television animation bring unlimited charm ${ }^{[2]}$. 3D animation production is divided to early roles, scenario modeling , the action design of role, assuming virtual camera , adding textures to the model, according to the need of scene designing lighting, render output to the consecutive pictures. And the all lens generate is finished, you can edit and combine them and add to sound effects for them using software in the late stage creation ,and the three-dimensional cartoon is finally finished. The usually using 3D software in the is television animation and special efficacy creating include Maya , 3ds Max .

\section{The problem of television animation industry in China}

Television animation product lack of creativity . According to the recent survey ,if select the favorite nineteen television animation image of China 's young people, you can find that the eighteen television animation images are come from overseas .and the only one the television animation image of China is Wukong Sun. The Wukong Sun image you can find in the figure .1 .This data illustrated that the creativity of television animation products of China is very scarcity . And lack of creativity of China 's television animation is reflect many aspect including the lack of original animation image, the relatively narrow of selection range and the not deep enough of culture penetration . 


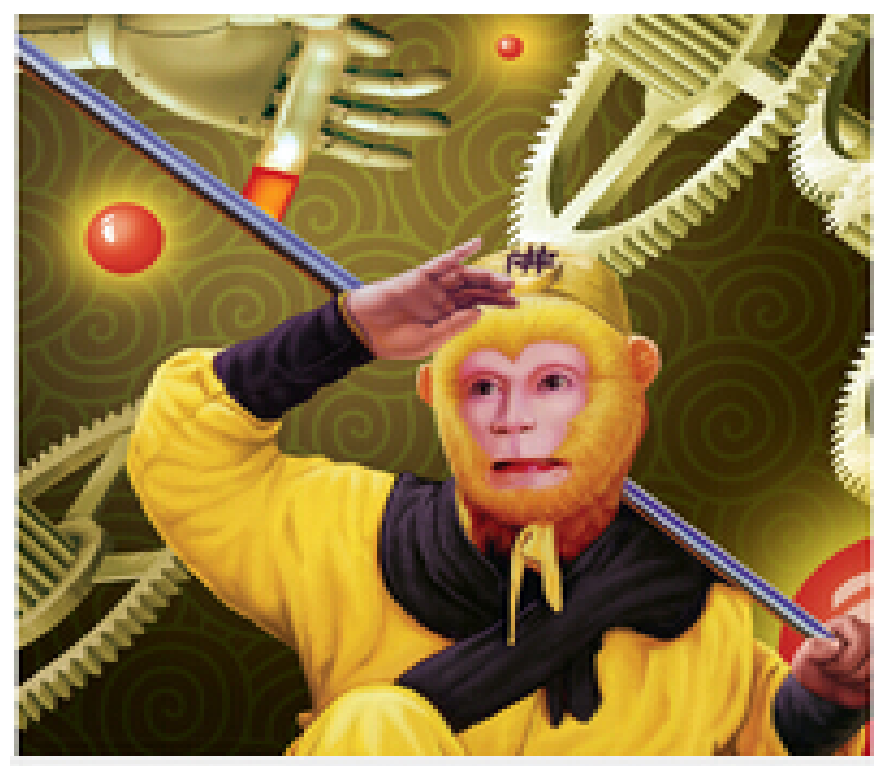

Figure.1 the animation image Wukong Sun

The constraints of traditional ideas . Because the influence of traditional ideas, the Chinese often think that television animation works are more suitable to Children , and it does not belong to Chinese cultural industry. Chinese's traditional ideas impede the development of television animation .

The lack of complete industrial chain . The industrial chain of television animation is make the creativity to be center, and it have two manifestations that include animation and cartoon , it also need the film and television to spread. For now , the annual output value of the world's television animation industry and some relation production products has exceeded four hundred billion , and it depend on the mature television animation industry chain that include six steps : produce television animation , broad animation product, develop derivatives products, sell derivatives products , receive earnings and again produce. The most complete industrial chain of television animation was created by American and the company of DISNEY epitomizes the development model of televi

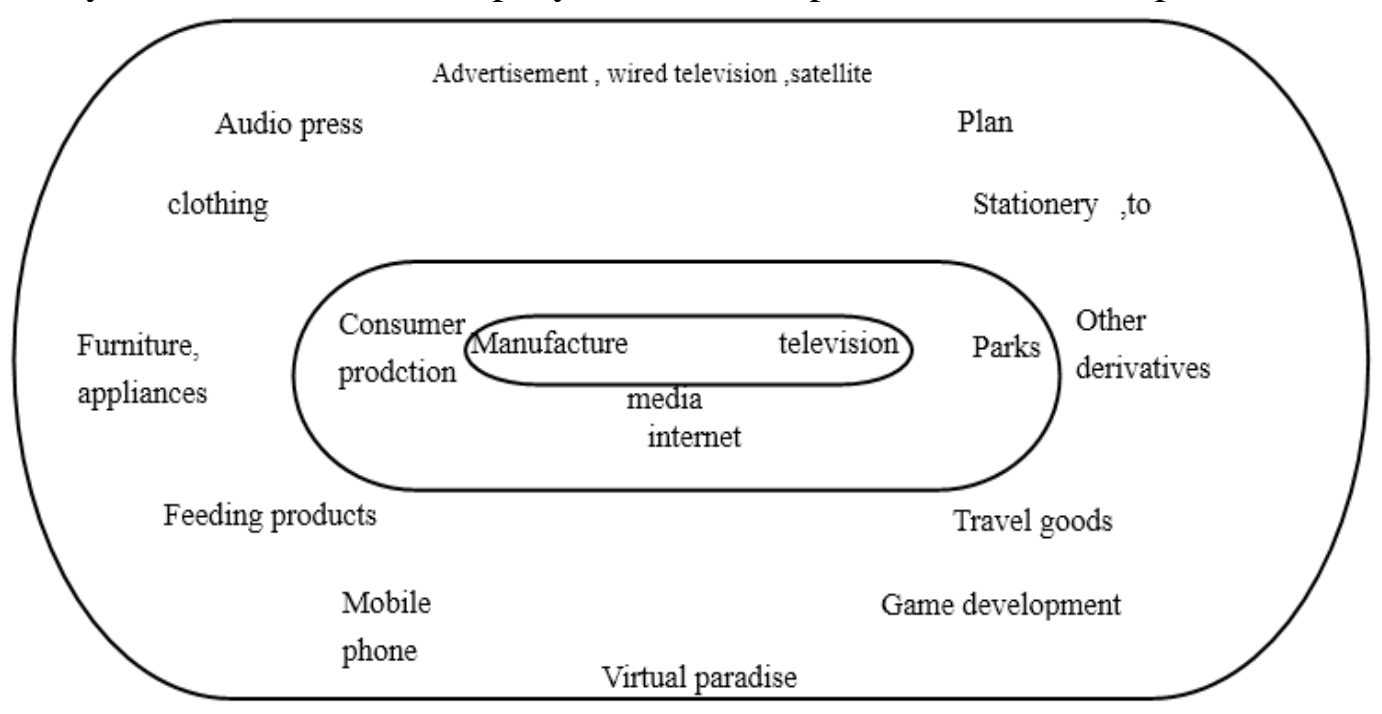

Figure .2 the compete industry chain of American animation

\section{The application of 3D digital technology in animation design production}

The application of 3D digital technology in animation role modeling design . An excellent animation works not only need it have vivid complete action drama , but also need it have role that have distinctive character. The application of 3D digital technology in animation design can change the plane of the role of traditional 2D animation, and make it have three-dimensional effect and realistic and make the audiovisual language of television animation more colorful . And it make 
the role modeling have real skin , hair and soft touch of clothes , as a result of the application of 3D digital technology, the movie star mickey mouse, donald duck of DISNEY company winning many people's favorite .

The application of 3D digital technology in animation scene design . The animation scene is the background that accompanied the development of story and role activities, and it include natural scene, social environment , history environment and the live environment of animation role . The animation scene digital based on 3D digital technology have different performance language with two-dimensional technology. The three-dimensional animation scene can analog complex nature system , using the function of light efficiency, particle systems ,and the camera show true lighting space and complex camera motion .

The application of 3D digital technology in animation role action design . The bright role action design can create the role image that can impress audience. The three-dimensional role action design convey information by using the facial expressions and body language . The role action of $3 \mathrm{D}$ animation is controlled by skeletal system, and it adjust action set by using the nonlinear time key frame .

\section{Conclusions}

3D digital technology is very important in the production of television animation , and it help animation add to new vitality . In the new period, the development of television animation need the support of 3D digital technology . Combine the advantages of 3D digital technology and the feature of television animation can promote the development of television animation .

\section{Acknowledgment}

This article for the following project there are results, respectively

1: the education of Hubei province "125" planning topics and Hubei university of Arts research project "based on cross media from the perspective of" experimental animation "curriculum teachin $\mathrm{g}$ and creative practice research" (project number: 2013B134), the one of the achievements .

2:the experimental study of "animation language form of Hubei Province Education Department of Humanities and social science research projects" (project number: 14G304), the one of the achievements .

\section{References}

[1] suzanne williams-Rautiola : book review of " prime time animation : Television animation and American culture ,” edited by arol A. Stabile and Mark Harrison . Popular communication , Vol.23(2005).No.12.P:234-237 .

[2] Yagang GUO : use of 3D computer animation technology in TV program production , Canadian social science, Vol.01(2014).No.4.P:456-459 .

[3] annonymous : key hire and new technology investments allow cinciMedia to expand capabilities into 3D animation and visual effects for television and film . Information technology business , Vol.23(2008).No.04.P:56-59. 